\title{
Effects of salt labelling and repeated in-home consumption on long-term liking of reduced-salt soups
}

\author{
Astrid A Willems, Danielle HA van Hout, Nicolien Zijlstra and Elizabeth H Zandstra* \\ Sensation, Perception \& Behaviour, Unilever R\&D Vlaardingen, Olivier van Noortlaan 120, PO Box 114, \\ 3130 AC Vlaardingen, The Netherlands
}

Submitted 16 September 2012: Final revision received 27 February 2013: Accepted 12 March 2013: First published online 1 May 2013

\begin{abstract}
Objective: The present study investigated the impact of salt labelling and repeated in-home consumption on liking of reduced-salt soups.

Design: Participants received a chicken noodle soup to be consumed twice weekly at home for 5 weeks. Three soups were included: (i) regular-salt soup as available on the market; (ii) $22 \%$-reduced-salt soup; and (iii) $32 \%$-reduced-salt soup. The soups were tasted blind or with the label: 'same great taste, less salt and more herbs'. In total, there were six experimental groups. All groups received the same soup over the whole period. Desire and liking were measured at each time of consumption.

Setting: In-home and central location test.

Subjects: French consumers ( $n$ 646).

Results: There was no significant difference in liking between the three soups when consumed at home, whereas the reduced-salt soups were less liked than the regular-salt soup in the central location test. Labelling did not boost liking scores, which is probably explained by the fact that all soups were similarly liked when eaten at home.

Conclusions: The surprising results of the present study in France suggest that a salt reduction of up to $32 \%$ in a chicken noodle soup did not affect long-term liking score as assessed by consumers at home. In addition, initial liking measured at the central location was not predictive of liking after repeated in-home consumption. How far we can go in reducing salt in other products without compromising product quality, and how this impacts consumers' choice behaviour and in turn table salt use at home, are still unanswered questions.
\end{abstract}

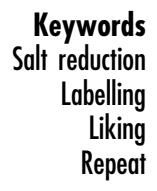

Generally, salt (sodium chloride: $\mathrm{NaCl}$ ) intake is much higher than the WHO-recommended level of $5 \mathrm{~g} / \mathrm{d}^{(1,2)}$. A high salt intake has been shown to lead to increased blood pressure and is a major cause of $\mathrm{CVD}^{(3-5)}$. Most salt intake is due to 'hidden salt' in processed foods ${ }^{(6,7)}$. Therefore, salt levels in food manufactured by industry need to be reduced. The food industry has already successfully lowered salt levels in many processed foods ${ }^{(8-10)}$ without the consumer being aware of this. Nevertheless, the need for more salt reduction in consumer products remains pressing and we have now arrived at the point where further reductions in salt might affect taste and liking of these products.

There is surprisingly little known about consumers' taste perception and liking of reduced-salt products. A few studies have shown that people can increase their liking for reduced-salt products ${ }^{(11-14)}$. In these studies participants shifted their optimal preferred salt level towards lower salt concentrations. The relationship between liking and salt intensity is described in an 'optimum salt curve' in which a certain salt concentration in food is preferred the most, and higher and lower concentrations are liked less ${ }^{(15-17)}$. This curve is different for each individual and is based among other factors on prior food experience and customary use of salt and salty products in the diet ${ }^{(13,16,18,19)}$. Ultimately, it is important to shift this curve to lower salt concentrations and the studies mentioned above indicate that it is possible to 'learn' to prefer products with lower salt concentrations. However, in those studies, participants were placed on extreme salt-restricted diets for several weeks to months in a row. This is different from everyday life: in practice, only a few single products within the total diet will be reduced in salt.

From the studies available on consumer's liking of single reduced-salt products, it seems that liking for these reduced-salt products remains within an acceptable range ${ }^{(14,20-25)}$. However, the taste and other aspects of these reduced-salt products do differ perceivably from their regular-salt counterparts and consumers have to be 
motivated to repeatedly try these reduced-salt products before they start learning to like them. Therefore, further attention to increase consumers' liking of reducedsalt products is required, alongside new approaches to reach this goal. Communication might be one of these approaches to compensate for, or manage expectations of, reduced-salt products.

Previous studies showed that communication can create expectations that influence taste perception and liking. For example, assimilation effects on liking have been shown for marketing communications, such as brand $^{(26,27)}$ and price ${ }^{(28,29)}$. Also, nutritional information with regard to fat ${ }^{(30)}$ and sugar ${ }^{(31)}$ increased the liking for these products. In contrast, labelling on ingredients (i.e. soya content in an energy bar) resulted in lower liking scores $^{(32)}$. Recent research of Liem et al ${ }^{(33)}$ found similar results on salt; placing the label 'now with reduced salt' on a soup decreased expected liking and perceived salt intensity even though all of the soups in their study had the same salt content. A follow-up study showed that this labelling may not just impact immediate taste perception but may drive compensatory salt use, even to the point of overcompensating ${ }^{(34)}$. Communication can thus have positive and negative effects on taste perception and liking, and to phrase the salt label in an optimal way is very important.

Currently, little is known about the impact of communication on long-term liking of reduced-salt products. Almost no scientific data are available regarding whether communication can compensate for perceivable reduced salt levels in food products. Therefore, the aim of the present study was to investigate the impact of communication around salt on long-term liking of reduced-salt soups. Liking was investigated in a natural in-home context over several weeks to reflect an everyday situation. In addition, we conducted a central location test just before and directly after the in-home use period - to investigate whether liking obtained at the central location would predict liking obtained at the repeated in-home consumption. We hypothesized that positive communication on salt reduction would increase liking of the reduced-salt soups in the long run.

\section{Methods}

\section{Participants}

The study took place in Paris (France) and a total of 646 French adults (26\% male) participated. Individuals were recruited by an external market research agency (Quovadis, Germany) and were included in the study if they were: aged 18-65 years; did like chicken noodle soup (scoring $\geq 4$ on a 7-point scale); were main brand users of dry soup products; were responsible for the groceries; and consumed dry soups at least once every two weeks. By means of a screening questionnaire, potential partici- pants were divided into three 'salt-interest-and-action' groups, based on the five stages of the Trans Theoretical Model of Behavioural Change ${ }^{(35)}$, i.e. 'no interest and no action' group (stage 1), 'interest but no action' group (stages 2 and 3) and 'interest and action' group (stages 4 and 5). Men and women, age groups and salt-interestand-action groups were equally divided across test conditions. The study was performed according to ESOMAR guidelines ${ }^{(36)}$ and individuals were paid for participation.

\section{Test products}

Three dry soups varying in salt content were included in the study: (i) a benchmark product, which was a chicken noodle soup available on the market in France at that time $(370 \mathrm{mg} \mathrm{Na} / 100 \mathrm{ml}$ prepared soup); (ii) a $22 \%$ reduced-salt soup (290 $\mathrm{mg} \mathrm{Na} / 100 \mathrm{ml}$ prepared soup); and (iii) a $32 \%$-reduced-salt soup ( $250 \mathrm{mg} \mathrm{Na} / 100 \mathrm{ml}$ prepared soup). The recipe for all soups was the same, only the salt content was different. Each dry soup was packed in a white sachet of dimensions $11 \mathrm{~cm} \times 16 \mathrm{~cm}$ with a coloured sticker measuring $8 \mathrm{~cm} \times 4 \mathrm{~cm}$ that contained the communication message (see below) and the Knorr brand name and logo. The soups were specifically developed for the present study (Unilever, Heilbronn, Germany). The levels of salt selected for the study were chosen based on the results of two pilot studies. All soups were first tested by eleven trained sensory panellists to ensure that only products that were clearly different in perceived saltiness intensity would be included in the main study. As expected, saltiness of the reduced-salt soups differed from the benchmark (2-AFC difference test; $P<0 \cdot 05)$. Additionally, the soups were tested by 105 French consumers in a central location test in a 'sip test' where consumers only tasted one spoonful. The consumers from this pilot study did not participate in the main study. The three soups did not differ in liking in the pilot study (benchmark: 4.6 (sD 1.8); $22 \%$-reduced-salt: 4.6 (SD 2.1); $32 \%$-reduced-salt: 4.3 (sD 1.9 ); $P>0.05$ on a 10-point scale) and were moderately liked, which assured that an increase in liking after repeated consumption was possible.

\section{Study procedures}

The study was divided into three steps. In step 1 all individuals participated in a central location test (CLT 1) in which the three soups were evaluated in random order. Approximately $75 \mathrm{ml}$ of soup was offered at about $65^{\circ} \mathrm{C}$ in small transparent plastic cups. The following questions were asked: 'Please indicate how much you look forward to eat this soup right now', 'Please taste the product and indicate how much you like the product', 'What, if anything, did you particularly like about the product?' and 'What, if anything, did you particularly dislike about the product?'. The first two questions had to be answered on a 7-point scale ranging from 'not at all' to 'very much' and 'don't like it all' to 'like it very much'. The last two questions were open answer questions. 
Table 1 Mean scores and standard deviations indicating to what extent French consumers $(n$ 646) agreed with statements regarding knowledge, attitudes and behaviour of salt reduction (from 1 = 'strongly disagree' to 7 = 'strongly agree')

\begin{tabular}{lr}
\hline Statements regarding knowledge, attitudes and behaviour on salt & Mean \\
\hline A too high salt intake increases my blood pressure & $5 \cdot 3$ \\
I have heard about the risks of eating too much salt & $5 \cdot 9$ \\
Lowering my salt intake decreases my risks of getting cardiovascular disease & $5 \cdot 5$ \\
Products like bread and cheese contain low salt levels & $3 \cdot 4$ \\
I believe I eat too much salt & $4 \cdot 0$ \\
I don't care about my salt intake - the important thing is the taste & $3 \cdot 5$ \\
Eating less salt is healthier for my family & $5 \cdot 8$ \\
I believe that lowering my salt intake will improve my health & $1 \cdot 3$ \\
I don't care about the amount of salt in products & $1 \cdot 6$ \\
I buy salt reduced products & $1 \cdot 7$ \\
I always add salt during the cooking process & $1 \cdot 8$ \\
I eat too many salty foods like potato chips & $1 \cdot 2$ \\
I don't put table salt on the table during dinner & $1 \cdot 3$ \\
\hline
\end{tabular}

In step 2, participants were divided into six groups and received one of the three soups to use at home for 5 weeks, either with or without communication on the package. Participants were not informed on the real aim of the study but were told that the study consisted of tasting and consuming soups over a 5 -week period at home. For the communication message on the packages we chose 'same great taste, less salt and more herbs'. This is a positively framed message and does not focus only on salt. Participants were asked to consume one full portion of the soup twice weekly. One pack of soup was enough for 1 litre of soup, so participants were able to consume the soups with their family at a conveniently chosen time (e.g. a moment that they would normally consume soup). With the packs of soups participants also received preparation instructions for the soup. Before and during consumption, participants (but not their family) were asked to answer the following questions: 'How hungry are you at this moment?', 'How thirsty are you at this moment?', 'Please indicate how much you want this soup right now?', 'Please taste the product and indicate how much you like the product' and 'How did you consume the soup?'. All questions could be answered on 7-point scales except for the last question which could be answered by selecting one of the following possibilities: 'alone', 'with the whole family' or 'with part of the family'.

In step 3, all individuals again participated in a central location test (CLT 2; identical to step 1). Additionally, salt interest and action state based on the Trans Theoretical Model of Behavioural Change ${ }^{(35)}$ was again assessed (same as in the screening questionnaire). Subsequently, the level of knowledge, attitudes and behaviour regarding salt was measured by asking participants to what extent they agreed with thirteen statements (from $1=$ 'strongly disagree' to $7=$ 'strongly agree'; Table 1).

\section{Statistical analysis}

Data are presented as means and standard deviations. Statistical analyses were performed using the SPPS statistical software package version $16 \cdot 0$. A value of $P<0.05$ was used as criterion for statistical significance.

To evaluate changes in product ratings over time in the in-home period, individual-level regression analyses were performed to calculate individual slopes over time with the product ratings (desire and liking) as the dependent variables and time (exposure days) as the independent variable. These slopes served as an overall measure of the rate of change over time (i.e. increase, stable or decrease pattern), and were subsequently analysed with a $2 \times 3$ ANOVA testing the effects of communication, product and their interaction on changes in desire and liking. Hunger and thirst ratings in the in-home period were analysed by twoway ANOVA including test group and time (exposure days).

Differences between the two central location tests in desire and liking were analysed with paired $t$ tests. Differences between soups (in the same central location test) were analysed with one-way ANOVA. To investigate if the specific soup consumed during the in-home period affected the ratings of the second central location test, a separate ANOVA was performed within the subgroups. Additionally, mean liking ratings obtained at the central location test and at home were analysed with paired $t$ tests within each experimental group, to test whether liking measured at the central location test (before and after) would predict liking during the repeated in-home consumption. Both $t$ tests using the average in-home rating (as reported) and individual in-home ratings on each day were performed (data not shown as they did not affect the conclusion).

The knowledge, attitudes and behaviour statements measured during the second central location test were analysed between the different experimental groups with one-way ANOVA.

\section{Results}

\section{In-bome use period}

On average, all soups were moderately to well liked, with mean scores ranging from $4 \cdot 4$ to $4 \cdot 8$ on 7 -point scales on 

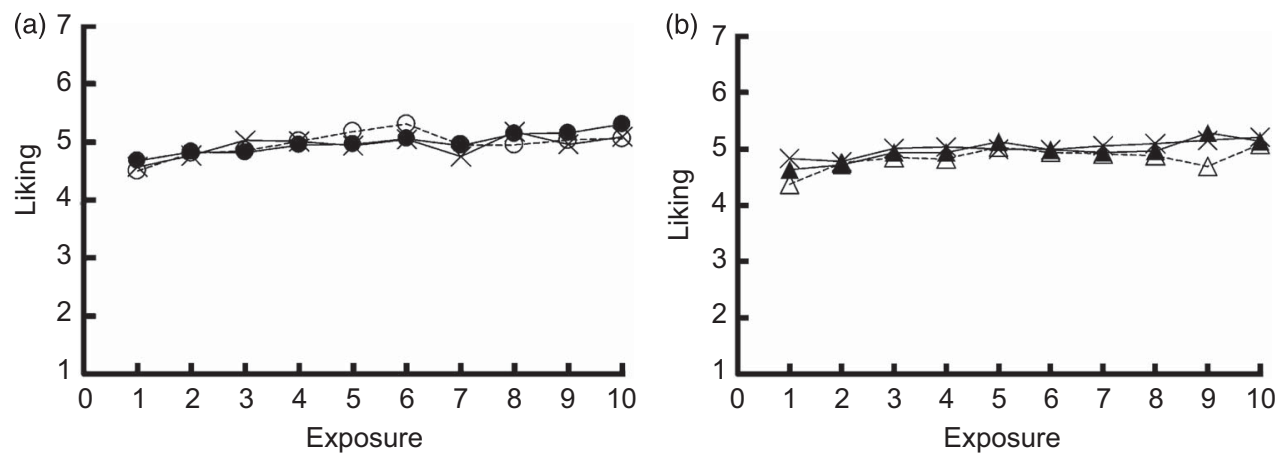

Fig. 1 Liking of the regular-salt soup (benchmark, $-\times-)$ and the $22 \%(-\mathbf{-},-\mathbf{\Delta}-)$ and $32 \%(--\circ--,--\triangle--)$ reduced-salt soups over time (5 weeks, two exposures per week) among French consumers $(n 646)$, measured on a 7 -point scale (from $1=$ 'not liked at all' to $7=$ 'liked very much'), for groups (a) with communication (- - - , - - - -) and (b) without communication ( $-\mathbf{\Delta}-,--\triangle--)$
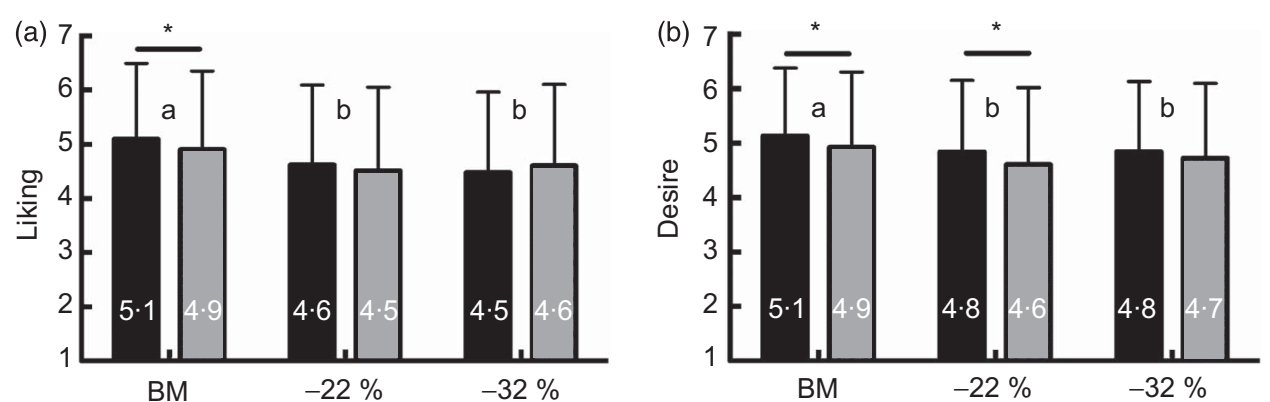

Fig. 2 Liking (a) and desire (b) for the regular-salt soup (benchmark (BM)) and the $22 \%$ and $32 \%$ reduced-salt soups in the first $(C L T 1, \square)$ and second (CLT 2, ) central location test among French consumers ( $n$ 646), measured on a 7-point scale (from $1=$ 'not liked at all'/'not desired at all' to $7=$ 'liked very much'/'desired very much'). Values are means with their standard deviations represented by vertical bars. Mean values were significantly different between CLT 1 and CLT 2 for the same soup: ${ }^{*} P<0 \cdot 05$. ${ }^{\mathrm{a}, \mathrm{b}}$ Mean values for products with unlike superscript letters were significantly different $(P<0.05)$

the first exposure day. Liking scores increased slightly over time for all soups $(P<0 \cdot 05 ;$ Fig. 1$)$. In contrast to our hypothesis, communication had no effect on liking scores; mean liking scores for the 'with communication' and 'without communication' groups were not statistically significantly different $(P>0 \cdot 05)$. The increase in liking in both the 'with communication' and 'without communication' groups was also equally strong. Interestingly, there were no differences in liking scores between the three different soups, i.e. between the benchmark soup and the reduced-salt soups $(P>0 \cdot 05)$.

Desire to eat the soup remained stable over time with on average a score of $5 \cdot 3(\mathrm{sD} 0 \cdot 8)$. There was no main effect of product or communication on desire-to-eat scores, i.e. scores were not significantly different between the three soups or between the 'with communication' and 'without communication' groups $(P>0.05)$.

Hunger and thirst scores were not significantly different between groups or between consumption days $(P>0 \cdot 05)$. Average ratings were $5.2(\mathrm{SD} 1.3)$ for hunger and $4.5(\mathrm{SD} 1.5)$ for thirst.

In most cases the soup was consumed alone, on average in $59 \%$ of the cases $v .20 \%$ consumed with the family or $21 \%$ with part of the family.

\section{Central location tests before and after the in-bome use period}

Figure 2 shows the liking and desire ratings of the three soups as measured in CLT 1 and CLT 2. The benchmark soup received significantly higher liking and desire ratings than the reduced-salt soups in both central location tests $(P<0 \cdot 05)$. Both reduced-salt soups were comparable in liking and desire. Comparing the results of the central location test before the in-home use period with the one after the in-home use period showed a small but significant decrease in liking for the benchmark soup (from $5 \cdot 1$ (sD $1 \cdot 4$ ) to $4 \cdot 9$ (sD $1 \cdot 4$ ); $P<0 \cdot 05$ ). No significant differences in liking between the two tests were found for the reduced-salt soups. Desire also showed a small but significant decrease after the in-home use period for the benchmark and the $22 \%$-reduced-salt soup (mean scores before $5 \cdot 1(\mathrm{sD} 1 \cdot 2)$ and $4 \cdot 8(\mathrm{sD} 1 \cdot 3)$, mean scores after $4 \cdot 9$ (SD 1.4) and 4.6 (SD 1.4) for respectively the benchmark and $22 \%$-reduced-salt soup; $P<0 \cdot 05$ ).

The second central location test was not significantly affected by the specific product that was consumed during the in-home use period $(P>0 \cdot 05)$.

The open answers to the questions about which aspects participants particularly liked or disliked about 
Table 2 Mean liking scores and standard deviations of the three soups with and without communication, obtained at the first (CLT 1) and second (CLT 2) central location test and at home, specified for the six groups according to the soup they repeatedly consumed at home, among French consumers $(n 646)$. Paired $t$ tests were used to compare the liking scores of the central location tests with the average inhome scores

\begin{tabular}{|c|c|c|c|c|c|c|c|c|c|c|}
\hline \multirow[b]{2}{*}{ Group } & \multirow{2}{*}{$\begin{array}{l}\text { Product repeatedly } \\
\text { consumed at home }\end{array}$} & \multirow{2}{*}{$\begin{array}{l}\text { Communication } \\
\text { on pack }\end{array}$} & \multicolumn{2}{|c|}{$\begin{array}{c}\text { Liking CLT } 1 \\
\text { for soup consumed } \\
\text { at home }\end{array}$} & \multicolumn{2}{|c|}{$\begin{array}{l}\text { Liking CLT } 2 \\
\text { for soup consumed } \\
\text { at home }\end{array}$} & \multicolumn{2}{|c|}{$\begin{array}{c}\text { Liking } \\
\text { in-home* }\end{array}$} & \multirow{2}{*}{$\begin{array}{l}P \text { value } \\
\text { CLT } 1 v \text {. } \\
\text { in-home* }\end{array}$} & \multirow{2}{*}{$\begin{array}{l}P \text { value } \\
\text { CLT } 2 v \\
\text { in-home }\end{array}$} \\
\hline & & & Mean & SD & Mean & SD & Mean & SD & & \\
\hline $1(n$ 101) & Benchmark soup & Yes & $5 \cdot 0$ & $1 \cdot 3$ & $4 \cdot 8$ & $1 \cdot 5$ & 4.9 & 0.8 & 0.45 & $0 \cdot 30$ \\
\hline $2(n 107)$ & $22 \%$-reduced-salt soup & Yes & $4 \cdot 7$ & 1.5 & $4 \cdot 8$ & $1 \cdot 4$ & $5 \cdot 0$ & 0.8 & 0.03 & 0.2 \\
\hline $3(n 117)$ & $32 \%$-reduced-salt soup & Yes & $4 \cdot 6$ & $1 \cdot 6$ & $4 \cdot 7$ & 1.5 & $5 \cdot 0$ & 0.8 & 0.006 & 0.03 \\
\hline $4(n 103)$ & Benchmark soup & No & $5 \cdot 1$ & $1 \cdot 4$ & $4 \cdot 8$ & $1 \cdot 3$ & $5 \cdot 0$ & 0.7 & 0.78 & $0 \cdot 11$ \\
\hline $5(n 112)$ & $22 \%$-reduced-salt soup & No & $4 \cdot 6$ & $1 \cdot 4$ & $4 \cdot 4$ & $1 \cdot 6$ & $5 \cdot 0$ & 0.8 & 0.002 & $<0.0001$ \\
\hline $6(n 106)$ & $32 \%$-reduced-salt soup & No & $4 \cdot 5$ & 1.5 & $4 \cdot 6$ & $1 \cdot 4$ & $4 \cdot 8$ & 0.8 & 0.02 & $0 \cdot 18$ \\
\hline
\end{tabular}

*Liking in-home is the average of the ten liking scores at home across the 5 weeks.

the products could be categorized into taste, smell, visual and textural aspects (data not shown).

\section{Central location compared with in-bome use}

Table 2 shows the effect of testing location (i.e. CLT 1, CLT $2 v$. at home) on the liking of the soups. The benchmark soups when eaten at home received similar liking scores to those when tasted at the central location $(P>0 \cdot 05)$. However, the reduced-salt soups were scored significantly higher in liking when eaten at home than when tasted at the central location $(P<0 \cdot 05)$.

\section{Knowledge, attitudes and bebaviour}

The mean scores showing to what extent participants agreed with the statements regarding knowledge, attitudes and behaviour of salt reduction are presented in Table 1. There were no statistically significant differences between the six experimental groups. This indicates that participants with different states of knowledge, attitudes and behaviours were equally divided over the six experimental groups.

\section{Discussion}

The present study investigated the impact of salt labelling and repeated in-home consumption on long-term liking of reduced-salt soups. Beforehand, we expected the reduced-salt soups to be less liked compared with the regular-salt product and that communication would lead to an increased acceptance. However, contrary to our expectations, there was no significant difference in liking between the three soups when consumed at home, whereas the reduced-salt soups were less liked than the regular-salt soup in the central location test. Labelling did not boost liking scores, which is probably explained by the fact that all soups were similarly liked when eaten at home. In addition, results showed that initial liking measured at the central location was not predictive of liking after repeated in-home consumption. Further research with other reduced-salt soups under realistic choice conditions in a natural context is needed to confirm these conclusions.

Salt is commonly used to provide saltiness, to enhance the general flavour of a food and to interact with other flavour elements, e.g. reduce bitterness ${ }^{(37)}$. The great challenge is therefore to reduce salt while maintaining the good taste of the original product to ensure consumer liking and enjoyment. In our study, we expected that the reduced-salt soups would be less liked than the regularsalt soup: the salt $(\mathrm{NaCl})$ was removed and not replaced by other salts or adjusted for in the recipe, which resulted in three soups that clearly differed in perceived saltiness. In contrast to expectations, we found no significant difference in liking between the three soups when consumed at home, whereas the reduced-salt soups were less liked than the regular-salt soup in the central location test. This decreased hedonic discrimination in in-home testing confirms previous research ${ }^{(38-41)}$ and shows that the influence of the eating environment on liking can be powerful. During the central location test, participants received a small portion of soup (approximately $75 \mathrm{ml}$ ) which had to be tested alone in isolation, in a laboratory test environment. This is completely different from the inhome situation, in which participants consumed a full portion of the soup, at a moment chosen by the participant him- or herself, in a familiar context and at times in the presence of family and friends. The latter could have had a positive influence on the evaluation of the soups. Previous studies also showed that the preference for test products is higher in in-home tests compared with central location tests ${ }^{(38,39)}$ and that context variables such as the function of the product as a meal component, social interaction, the environment of consumption and freedom of food choice significantly affect product evaluation in a positive direction ${ }^{(40-42)}$

Another reason for the similar liking scores of the soups eaten at home could be that participants may have added salt back themselves. A disadvantage of the in-home testing is that one has less control over the use of the products. For instance, we do not know how participants 
have prepared or consumed the soups at home. It is possible that they added more or less water than instructed and thereby changed salt concentrations or that they added salt or flavour enhancers to the soups, which could explain the unexpected liking scores. It was a deliberate choice not to check salt use at the table or while cooking to maintain the manner of consumption as natural as possible. On a daily basis it is estimated that salt from table salt and cooking is only responsible for approximately $10 \%$ of total salt intake compared with approximately $75 \%$ from processed and restaurant foods ${ }^{(6,7,43,44)}$. In addition, Beauchamp et al. ${ }^{(45)}$ and Shepherd et $a l^{(46)}$ showed that participants do not fully compensate via salt shaker for the reduced salt content of their diet or meal, compensation was only $22 \%$ and $20 \%$ respectively. Interestingly, a recent laboratory study by Liem et $a l .{ }^{(34)}$ showed the contrary: participants who received reduced-sodium soups were much more likely to add salt, even to the point of overcompensating. The latter also suggests that explicit questions on liking may be less sensitive to the effects of reduced-salt formulations than other behavioural measures. Therefore, future studies need to include direct measures on: (i) table salt use, to quantify to what extent participants compensate for reductions in salt; and (ii) preference, as more pronounced changes may be demonstrated in terms of preference rather than liking ${ }^{(47)}$.

In the present study, we probably did not shift the 'optimum salt curve' towards a lower preferred salt level as the regular-salt soup was still slightly preferred over the reduced-salt soups in the second central location test. We know that shifting this optimum is possible when the total diet is reduced in salt for an extended period of time ${ }^{(8,9)}$. Together, our observations with a single reduced-salt product in the diet support the notion that it requires a higher exposure frequency over a longer period of time to establish a clear shift in the optimum.

So far, two studies have shown that it is possible to gradually reduce salt content in a single product in small steps over time ${ }^{(14,21)}$. For instance, Girgis et al. ${ }^{(21)}$ showed a successful strategy of reducing salt content in bread. Participants' usual bread was replaced by the study bread for a period of 6 weeks. Gradually, the salt content of the study bread was decreased in steps of $5 \%$, resulting in the end in a reduction of about $25 \%$. Although they found significantly declining saltiness scores in the group receiving the reduced-salt bread compared with the control group (bread with usual salt content), they found no differences in liking for the breads. In addition, a few single taste-test studies showed generally that a 20-30\% reduction of salt was still acceptable, although this was product specific ${ }^{(22,25,48,49)}$. A current challenge lies in getting consumers to try these products repeatedly, so that they adapt slowly to these product changes over time and eventually shift the optimal preferred salt level.

To date it remains unknown if labels not only influence consumers' taste perception but also choice of saltreduced products. In our study, consumers were not free to choose among different versions of soups (e.g. highsalt $v$. low-salt). Having a choice would more closely reflect the everyday situation in the supermarket and at home, where consumers can choose from several products from different brands. Also, if consumers do not choose reduced-salt products several times it is possible that the number of exposures is not high enough to shift the optimum and hence increase the liking of the foods. Especially, if one industry partner will reduce the salt content of their products whereas the other does not, it might be hard for consumers to learn to like the taste of reduced-salt foods. This advocates for an industry-wide plan to reduce the salt content of certain food segments simultaneously. In fact, not only industry but several stakeholders, e.g. government, public health organisations, chefs, scientists, health-care professionals and also consumers, need to work together and take their responsibility in order to achieve large reductions in salt intake ${ }^{(8,50)}$.

Liem et al. ${ }^{(33)}$ showed that on-pack reduced-salt labels can have a negative impact on consumers' expectation and taste perception of salt-reduced products: consumers believed it will be less tasty. In the current study, we framed the salt label in a different, more positive way compared with the one in the study of Liem et al. ${ }^{(33)}$, i.e. from 'now with reduced salt' to 'same great taste, less salt and more herbs', but interestingly this re-framing of the message did not have any effect on liking. Preferably, we would have included a broader range of products (i.e. clearly varying in liking as intended) across different product categories and using different types of messages to investigate the effects of on-pack salt labelling on longterm liking in a more structural way. This would then have provided a clear opening for communication messages that are framed in such a way that it is motivating for consumers to choose salt-reduced products, not only once but repeatedly over time ${ }^{(51)}$.

Finally, the question remains how best to implement these results. The results are found for one specific product, i.e. chicken noodle soup, in one country, i.e. France. From unpublished internal data the authors are aware that salt reduction possibilities depend very much on product type, usage, consumers' interest and awareness around salt reduction, and all need a different approach. To meet the WHO-recommended level of $5 \mathrm{~g}$ of salt daily, further reductions in the salt content of foods are required while maintaining good taste and consumer liking, as well as a change in attitudes and behaviour among consumers. Further studies in various countries are recommended to gain a better understanding of consumers' interest in salt reduction and motivation to change towards reduced-salt alternatives, i.e. population-based perceptions regarding salt and level of intake, drivers of intake, how people use salt and preferred ways of communication. These findings will support ongoing development of effective global strategies for salt reduction. 


\section{Conclusion}

Research in the area of salt reduction is limited while the need for acceptable low-salt products is high. The present study showed that a salt reduction of up to $32 \%$ in a chicken noodle soup did not affect long-term liking scores obtained within a natural in-home context. In addition, initial liking measured at the central location was not predictive of liking after repeated in-home consumption. How far we can go in reducing salt in other products without compromising product quality, and how this impacts consumers' choice behaviour and in turn table salt use at home, are still unanswered questions.

\section{Acknowledgements}

Sources of funding: The study was funded by Unilever. Conflicts of interest: There are no conflicts of interest to declare. Ethics: The study was not approved by an ethical committee, but was performed according to ESOMAR guidelines (2010). Authors' contributions: A.A.W. helped design the experiment, collected and analysed the data, and contributed significantly to writing the manuscript, D.H.A.v.H. provided significant advice and consultation. N.Z. analysed the data and contributed significantly to writing the manuscript. E.H.Z. helped design the experiment and contributed significantly to writing the manuscript. Acknowledgements: The authors would like to thank Graham Cleaver for his critical help in the statistical analyses, Beatrijs Hauer and Gerda Feunekes for their valuable input in earlier versions of this paper, and Edouard Bonnet for the development of the soups.

\section{References}

1. World Health Organization (2003) Diet, Nutrition and the Prevention of Chronic Diseases. Report of a Joint WHO/FAO Expert Consultation. WHO Technical Report Series no. 916. Geneva: WHO.

2. Brown IJ, Tzoulaki I, Candeias V et al. (2009) Salt intakes around the world: implications for public health. Int $J$ Epidemiol 38, 791-813.

3. He FJ \& MacGregor GA (2003) How far should salt intake be reduced? Hypertension 42, 1093-1099.

4. He FJ \& MacGregor GA (2010) Reducing population salt intake worldwide: from evidence to implementation. Prog Cardiovasc Dis 52, 363-382.

5. Mohan S \& Campbell NRC (2009) Salt and high blood pressure. Clin Sci (Lond) 117, 1-11.

6. James WP, Ralph A \& Sanchez-Castillo CP (1987) The dominance of salt in manufactured food in the sodium intake of affluent societies. Lancet 1, 426-429.

7. Mattes RD \& Donnelly D (1991) Relative contributions of dietary-sodium sources. J Am Coll Nutr 10, 383-393.

8. Dötsch M, Busch J, Batenburg M et al. (2009) Strategies to reduce sodium consumption: a food industry perspective. Crit Rev Food Sci Nutr 49, 841-851.

9. Webster JL, Dunford EK, Hawkes C et al. (2011) Salt reduction initiatives around the world. J Hypertens 29, 1043-1050.
10. World Health Organization (2007) Reducing Salt Intake in Populations. Report of a WHO Forum and Technical Meeting, 5-7 October 2006, Paris, France. Geneva: WHO.

11. Bertino M, Beauchamp GK \& Engelman K (1982) Longterm reduction in dietary sodium alters the taste of salt. $\mathrm{Am}$ J Clin Nutr 36, 1134-1144.

12. Blais CA, Pangborn RM, Borhani NO et al. (1986) Effect of dietary sodium restriction on taste responses to sodium chloride: a longitudinal study. Am J Clin Nutr 44, 232-243.

13. Mattes RD (1997) The taste for salt in humans. Am J Clin Nutr 65, 2 Suppl., 692S-697S.

14. Bolhuis DP, Temme EHM, Koeman FT et al. (2011) A salt reduction of $50 \%$ in bread does not decrease bread consumption or increase sodium intake by the choice of sandwich fillings. J Nutr 141, 2249-2255.

15. De Graaf C, Van Staveren W \& Burema J (1996) Psychophysical and psychohedonic functions of four common food flavours in elderly subjects. Chem Senses 21, 293-302.

16. Zandstra EH, De Graaf C, Mela DJ et al. (2000) Short- and long-term effects of changes in pleasantness on food intake. Appetite 34, 253-260.

17. Drewnowski A, Henderson SA, Driscoll A et al. (1996) Salt taste perceptions and preferences are unrelated to sodium consumption in healthy older adults. J Am Diet Assoc 96, 471-474.

18. Tuorila-Ollikainen H, Salovaara H \& Kurkela R (1986) Effect of saltiness on the liking and consumption of bread and butter. Ecol Food Nutr 18, 99-106.

19. Sullivan SA \& Birch LL (1990) Pass the sugar, pass the salt experience dictates preference. Dev Psychol 26, 546-551.

20. Bolhuis DP, Lakemond CM, De Wijk RA et al. (2010) Effect of salt intensity on ad libitum intake of tomato soup similar in palatability and on salt preference after consumption. Chem Senses 35, 789-799.

21. Girgis S, Neal B, Prescott J et al. (2003) A one-quarter reduction in the salt content of bread can be made without detection. Eur J Clin Nutr 57, 616-620.

22. Kremer S, Mojet J \& Shimojo R (2009) Salt reduction in foods using naturally brewed soy sauce. J Food Sci $\mathbf{7 4}$, issue 6, S255-S262.

23. Lucas L, Riddell L, Liem G et al. (2010) The influence of sodium on liking and consumption of salty food. J Food Sci 76, issue 1, S72-S76.

24. Nakamura M, Aoki N, Yamada T et al. (2003) Feasibility and effect on blood pressure of 6-week trial of low sodium soy sauce and miso (fermented soybean paste). Circ J 67, $530-534$

25. Methven L, Langreney E \& Prescott J (2012) Changes in liking for no added salt soup as a function of exposure. Food Qual Prefer 26, 135-140.

26. Di Monaco R, Cavella S, Di Marzo S et al. (2004) The effect of expectations generated by brand name on the acceptability of dried semolina pasta. Food Qual Prefer 15, 429-437.

27. McClure SM, Li J, Tomlin D et al. (2004) Neural correlates of behavioral preference for culturally familiar drinks. Neuron 44, 379-387.

28. Lange C, Rousseau F \& Issanchou S (1999) Expectation, liking and purchase behaviour under economical constrains. Food Qual Prefer 10, 31-39.

29. Plassmann H, O'Doherty J, Shiv B et al. (2008) Marketing actions can modulate neural representations of experienced pleasantness. Proc Natl Acad Sci U S A 105, 1050-1054.

30. Kahkonen P, Tuorila H \& Rita H (1996) How information enhances acceptability of a low-fat spread. Food Qual Prefer 7, 87-94.

31. Kuenzel J, Zandstra EH, El-Deredy W et al. (2011) Expecting yoghurt drinks to taste sweet or pleasant increases liking. Appetite 56, 122-127. 
32. Wansink B \& Park SB (2002) Sensory suggestiveness and labeling: do soy labels bias taste? J Sens Studies 17, 483-491.

33. Liem DG, Aydin NT \& Zandstra EH (2012) Effects of health labels on expected and actual taste perception of soup. Food Qual Prefer 25, 192-197.

34. Liem DG, Miremadi F, Zandstra EH et al. (2012) Health labelling can influence taste perception and use of table salt for reduced-sodium products. Public Health Nutr 15, 2340-2347.

35. Prochaska JO, DiClemente CC \& Norcross JC (1992) In search of how people change. Applications to addictive behaviors. Am Psychol 47, 1102-1114.

36. ESOMAR (2010) ICC/ESOMAR International Code of Marketing and Social Research. http://www.esomar.org/ knowledge-and-standards/codes-and-guidelines.php (accessed November 2010).

37. Breslin PA \& Beauchamp GK (1997) Salt enhances flavour by suppressing bitterness. Nature 387, 563-563.

38. Boutrolle I, Arranz D, Rogeaux M et al. (2005) Comparing central location test and home use test results: application of a new criterion. Food Qual Prefer 16, 704-713.

39. Boutrolle I, Delarue J, Arranz D et al. (2007) Central location test vs. home use test: contrasting results depending on product type. Food Qual Prefer 18, 490-499.

40. King SC, Weber AJ, Meiselman HL et al. (2004) The effect of meal situation, social interaction, physical environment and choice on food acceptability. Food Qual Prefer 15, 645-653.

41. King SC, Meiselman HL, Hottenstein AW et al. (2007) The effects of contextual variables on food acceptability: a confirmatory study. Food Qual Prefer 18, 58-65.
42. Zandstra EH, De Graaf C \& Van Trijp HC (2000) Effects of variety and repeated in-home consumption on product acceptance. Appetite 35, 113-119.

43. Andersen L, Rasmussen LB, Larsen EH et al. (2009) Intake of household salt in a Danish population. Eur J Clin Nutr 63, 598-604.

44. Sanchez-Castillo CP, Warrender S, Whitehead TP et al. (1987) An assessment of the sources of dietary salt in a British population. Clin Sci (Lond) 72, 95-102.

45. Beauchamp GK, Bertino M \& Engelman K (1987) Failure to compensate decreased dietary sodium with increased table salt usage. JAMA 258, 3275-3278.

46. Shepherd R, Farleigh CA \& Wharf SG (1989) Limited compensation by table salt for reduced salt within a meal. Appetite 13, 193-200.

47. Zandstra EH \& El-Deredy W (2011) Effects of energy conditioning on food preferences and choice. Appetite 57, 45-49.

48. Adams SO, Maller O \& Cardello AV (1995) Consumer acceptance of foods lower in sodium. J Am Diet Assoc 95, $447-453$

49. Malherbe M, Walsh CM \& Van Der Merwe CA (2003) Consumer acceptability and salt perception of food with a reduced sodium content. Tydskrif vir Gesinsekologie en Verbruikswetenskappe 32, 12-20.

50. Busch J, Feunekes G, Hauer B et al. (2010) Salt reduction and the consumer perspective. New Food Mag 2, 36-39.

51. Zandstra EH, Miyapuram KP \& Tobler PN (2013) Understanding consumer decisions using behavioural economics. Prog Brain Res 202, 197-212. 